OPEN ACCESS

Edited by:

Erik Hofmeister,

Auburn University, United States

Reviewed by:

Ed Maibach,

George Mason University,

United States

Lisa Sams Ebner,

Lincoln Memorial University,

United States

*Correspondence:

Colleen G. Duncan

Colleen.Duncan@colostate.edu

Specialty section:

This article was submitted to

Veterinary Humanities and Social

Sciences,

a section of the journal

Frontiers in Veterinary Science

Received: 02 October 2020 Accepted: 11 November 2020 Published: 17 December 2020

Citation:

Kramer CG, McCaw KA, Zarestky J and Duncan CG (2020) Veterinarians

in a Changing Global Climate: Educational Disconnect and a Path

Forward. Front. Vet. Sci. 7:613620.

doi: 10.3389/fvets.2020.613620

\section{Veterinarians in a Changing Global Climate: Educational Disconnect and a Path Forward}

\author{
Collin G. Kramer ${ }^{1}$, Katherine A. McCaw ${ }^{1}$, Jill Zarestky ${ }^{2}$ and Colleen G. Duncan ${ }^{3 *}$ \\ ${ }^{1}$ College of Veterinary Medicine and Biomedical Sciences, Fort Collins, CO, United States, ${ }^{2}$ School of Education, Colorado \\ State University, Fort Collins, CO, United States, ${ }^{3}$ College of Veterinary Medicine and Biomedical Sciences, Department of \\ Microbiology, Immunology and Pathology, Fort Collins, CO, United States
}

Objective: To synthesize the beliefs, knowledge and interest of veterinarians on the relationship between veterinary medicine and climate change, with the intent to identify any educational gaps and opportunities.

Sample: Responses from 560 U.S., and 54 non-U.S. veterinarians.

Procedures: An anonymous, online survey of veterinarians was distributed through electronic media, state and professional associations, and a veterinary magazine advertisement. The survey was conducted between July 1st and December 31st of 2019.

Results: Overall, veterinary respondents were confident that climate change is happening, is caused by human activities, and is impacting both human and animal health. Veterinarians also agreed that the profession should have an advocacy role in educating the public on climate change and its health impacts, particularly in clinical practices where environmental sustainability promotion can be shared with clients. Although veterinarians agreed the profession needs to be involved with climate change advocacy, most reported having had no educational opportunities within their veterinary medicine curriculum or access to continuing education on climate change.

Conclusions and Clinical Relevance: The results highlight the need for the development of educational opportunities on the topic of climate change such that veterinarians are equipped to address their concerns about current and future animal health threats.

Keywords: climate change, education, veterinary medicine, sustainability, environment

\section{INTRODUCTION}

Action is urgently needed to mitigate the profound health threats arising from climate change. Human health professionals around the world have begun to address the issue and leadership is seen at all levels, from international organizations like the World Health Organization (WHO), to local community driven efforts $(1,2)$. In addition to an emerging field of research on the epidemiology, prevention, and response to climate associated illness, educators are working to integrate climate change into medical curricula $(3,4)$. These efforts are supported by governing bodies such as the American Medical Association who have enacted policy "aiding physicians in adopting environmentally-sustainable programs in their practices and sharing these concepts with their patients and communities" (5). Simultaneously, there 
are numerous initiatives underway to reduce the impact of healthcare delivery itself through environmentally sustainable practices in the clinical setting (6).

In contrast, the animal health community has been less enterprising in the area of sustainable animal health and climate change adaptation planning or action. In a recent survey of U.S. veterinary students, respondents highlighted a striking lack of educational opportunities on the topic despite their overwhelming belief that climate change is occurring and has health impacts for both people and animals (7). As doctors of many species with an established role in public and ecosystem health, veterinarians have the potential to meaningfully contribute to climate change action, however education and empowerment are necessary. Failure of veterinarians to engage on such a massive, global health issue has generated concerns for the social relevance of the profession (8).

It is unclear where the divide lies between the animal health community and action on climate change. While veterinary students highlighted educational gaps and concern for political disconnect with clients (7), it is not known if graduate veterinarians share the same perceptions. The objective of this study was to obtain veterinarians' opinions and knowledge about climate change and veterinary medicine, and to determine educational disparities and opportunities surrounding the topic.

\section{MATERIALS AND METHODS}

The study was based on analogous research projects targeting veterinary students (7) or physician groups (9-11). An anonymous survey of U.S. veterinarians was administered using online survey software ${ }^{1}$. The survey consisted of twentythree questions including multiple choice, ranking, and multiselect (Appendix 1). Questions were grouped into six categories including demographics, climate change beliefs and knowledge, health-related impacts of climate change, the role of veterinarians in climate change, barriers to veterinarians for addressing climate change, and climate change and health educational opportunities. The survey was reviewed and approved by the Colorado State University Institutional Review Board prior to distribution. The survey link was distributed to veterinarians through social media, state and interest group associations and an advertisement in a veterinary magazine. The survey was open from July 1st to December 31st, 2019. As no question mandated a response in order to complete the survey, data expressed as percentages represent valid percentages to exclude missing data from unanswered questions. The frequency of responses between groups was compared using chi-squared tests. Data analysis was conducted using commercially available software ${ }^{2}$.

\section{RESULTS}

\section{Demographics of Participants}

The survey link was accessed 651 times with 614 respondents answering at least one of the questions. Of the 614 respondents

${ }^{1}$ Qualtrics ${ }^{\circledR}$, Provo, UT.

${ }^{2}$ SPSS Statistics v25, IBM Inc., Armonk, NY.
TABLE 1 | Number of survey participants from each state of the 560 U.S.A. respondents.

\begin{tabular}{|c|c|c|c|}
\hline State & Participants & State & Participants \\
\hline Arizona & 27 & Missouri & 13 \\
\hline California & 31 & New York & 19 \\
\hline Colorado & 104 & North Carolina & 14 \\
\hline Florida & 14 & Ohio & 12 \\
\hline Georgia & 20 & Oklahoma & 12 \\
\hline Illinois & 10 & Pennsylvania & 10 \\
\hline lowa & 10 & Texas & 68 \\
\hline Kansas & 11 & Virginia & 19 \\
\hline Maryland & 19 & \multicolumn{2}{|c|}{ Participants from states with $<10$ responses, } \\
\hline Minnesota & 17 & state not reported or multiple states: & 149 \\
\hline
\end{tabular}

who provided location information, the overwhelming majority $(91.2 \%, 560 / 614)$ were from the U.S. and 54 were from 15 other countries. Data was stratified by U.S. and non-U.S. respondents for further analysis. Of the respondents from the U.S., there was at least one respondent from each state except for Hawaii, North and South Dakota (Table 1). Most survey participants were in the $30-39$ year age range $(35.2 \%, 184 / 522)$, followed by $40-49$ year age range $(21.1 \%, 110 / 522), 50-59$ year age range $(16 \%, 83 / 522)$, $<30$ years $(13.2 \%, 69 / 522), 60-69$ year age range $(10.7 \%, 56 / 522)$, and $>70$ years $(3.8 \%, 20 / 522)$. The majority of respondents were female $(73.9 \%, 400 / 541)$ followed by male $(25.5 \%, 138 / 541)$ and $(0.6 \%, 3 / 541)$ identifying as other or gender not listed.

The majority of U.S. respondents were employed in small animal clinical practice $(54.9 \%, 301 / 548)$, followed next by academia $(13.5 \%, 74 / 548)$, government $(10.4 \%, 57 / 548)$, mixed animal clinical practice $(6.9 \%, 38 / 548)$, other $(6.8 \%, 37 / 548)$, industry $(4.2 \%, 23 / 548)$, and large animal clinical practice $(3.3 \%$, 18/548). The most common employment sectors within the "other" category were non-profit shelter medicine $(13.5 \%, 5 / 37)$ and specialty medicine $(13.5 \%, 5 / 37)$, followed by wildlife $(10.8 \%$, $4 / 37)$, environmental/public health $(8.1 \%, 3 / 37)$, consulting $(5.4 \%, 2 / 37)$, equine medicine $(5.4 \%, 2 / 37)$, and lab animal $(2.7 \%, 1 / 37)$. Most participants were employed in suburban areas $(49.6 \%, 273 / 550)$, followed by urban areas $(26 \%, 143 / 550)$, rural areas $(20 \%, 110 / 550)$, areas other than those listed $(4 \%, 22 / 550)$, and those who felt they did not know how to describe the region in which they work $(0.4 \%, 2 / 550)$. The most common political belief of the respondents was somewhat liberal $(31.8 \%$, $76 / 553)$, followed by moderate $(24.8 \%, 137 / 553)$, very liberal $(19.3 \%, 107 / 553)$, somewhat conservative $(15.2 \%, 84 / 553)$, very conservative $(7.2 \%, 40 / 553)$, and other $(1.6 \%, 9 / 553)$.

\section{Climate Change Beliefs}

The overwhelming majority of U.S. participants (90.8\%, 505/556) agreed climate change is occurring at this time. Some participants [4.7\% (26/556)] think climate change is not occurring at this time, while $4.5 \%(25 / 556)$ felt they did not know if climate change is occurring. Those who believe climate change is occurring were more confident in their belief than those who do not believe in climate change (Figure 1). Veterinarians 
feel climate change is caused either mostly $(58 \%, 318 / 548)$ or about equally $(17 \%, 93 / 548)$ by human activities and natural changes in the environment. Some participants $(9.1 \%$, 50/548) think climate change is caused entirely by human activities. Even fewer believe climate change is caused mostly $(8.4 \%, 46 / 548)$ or entirely $(4 \%, 22 / 548)$ by natural changes in the environment. About $0.5 \%$ (3/548) of respondents think climate change is not happening, while $2.9 \%(16 / 548)$ felt they did not know what is causing climate change to occur.

\section{Climate Change and Health}

Generally, most U.S. veterinarians had some knowledge about the association between climate change and human health impacts with $39.2 \%(213 / 548)$ feeling moderately and $15.4 \%$ (84/548) feeling very knowledgeable (Figure 2). Veterinarians reported being similarly knowledgeable about the association between climate change and animal health impacts with $40.4 \%$ (220/548) feeling moderately and $14.9 \%$ (81/548) feeling very knowledgeable (Figure 2). Over half of the survey participants felt climate change is moderately $(43.4 \%, 238 / 548)$ or greatly

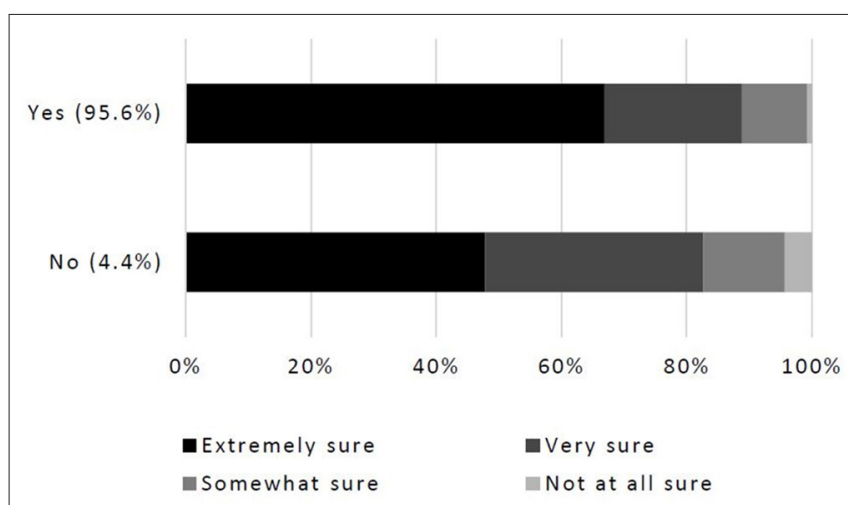

FIGURE 1 | Percentage of veterinarian participants who believe, or do not believe, that climate change is occurring and their level of confidence in that belief $(n=521)$.

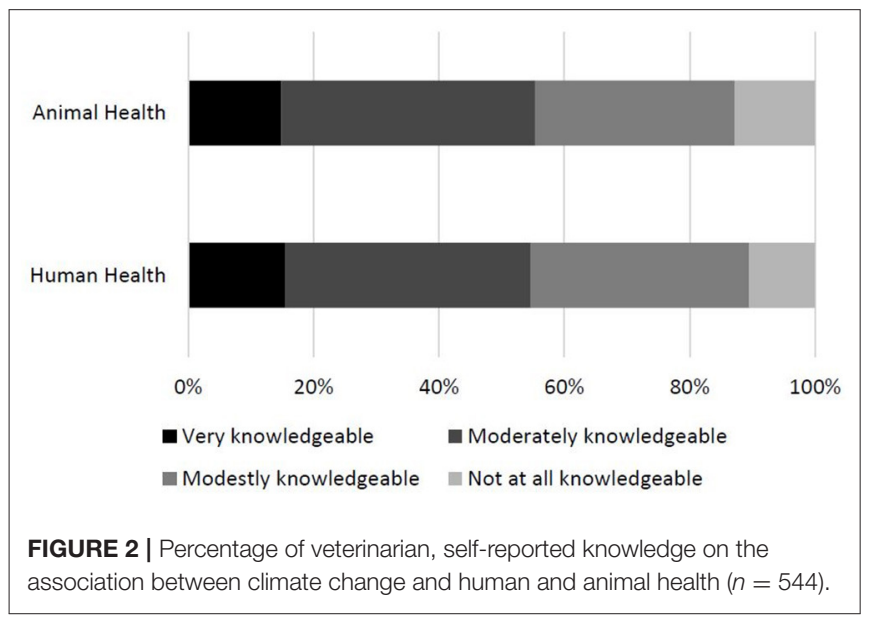

$(18.1 \%, 99 / 548)$ relevant to direct veterinary patient care. While $24.6 \%(135 / 548)$ of veterinarians felt climate change is only a little relevant to direct veterinary patient care, $7.8 \%$ (43/548) did not think it was relevant at all, and 6\% (33/548) did not know if it was relevant to direct veterinary patient care.

The ways in which veterinarians feel that veterinary patients are expected to be impacted by climate change, both now and in the future, are presented in Table 2. Vector-borne disease, extreme weather and heat-associated illness/stress were issues ranked highest of concern now, while vector-borne disease, extreme weather and declining air quality were the issues ranked the highest of concern for the future. Additional health impacts of concern to respondents included pollution, allergens, loss of medicinal resources found in nature, animal relinquishment or abandonment, loss of biodiversity and general destruction of natural ecosystems. When participants were asked to identify groups of animals they felt would disproportionately experience negative effects from climate change, they recognized rural wildlife $(70 \%, 392 / 560)$, production animals $(65.9 \%$, $369 / 560)$, animals owned or cared for by people with low socioeconomic status $(60.4 \%, 338 / 560)$, animals with underlying health conditions $(56.8 \%, 318 / 560)$, and urban wildlife $(55.9 \%$, $313 / 560)$ as the groups they considered to be at highest risk. Less than half of respondents identified older animals (45.4\%, 254/560), rural companion (35.4\%, 198/560), and urban companion animals $(33.8 \%, 189 / 560)$ at increased risk. Another $6.3 \%(35 / 560)$ of participants recognized "other" groups of animals as being at increased risk such as zoo and marine wildlife.

\section{The Role of Veterinarians}

Regarding participants' opinions of the role veterinarians play concerning climate change and health (Figure 3), there was strong agreement $(81.7 \%, 416 / 509)$ that veterinarians should have a leadership role in encouraging environmental sustainability amongst offices, clinics, and hospitals. Respondents felt veterinary medical societies should have a significant advocacy role in climate change and health $(71.5 \%, 366 / 512)$. Similarly, participants agreed $(69.7 \%, 357 / 512)$ that the actions they take in their personal and/or professional lives can contribute to effective action on climate change. They also agreed that teaching about the environment and its association with health impacts should be incorporated into veterinary medical education $(69.7 \%, 357 / 512)$. The least agreed upon statements, while still supported by more than half of the participants, were regarding the responsibility of veterinarians to bring health effects of climate change to the attention of the public (59.3\%, 303/511) and their clients (52.7\%, 268/509). Potential barriers that participants felt were likely to prevent veterinarians from addressing climate change-related health issues with clients can be found in Figure 4. Differences in political views damaging the veterinarian-client-patient relationship after discussing climate change was identified as the largest barrier $(77.7 \%, 397 / 511)$. Some respondents felt that addressing these issues with veterinary clients will not make much difference in their patients' overall health $(37.8 \%, 193 / 510)$. 


\section{Educational Opportunities on Climate Change}

When U.S. participants were asked about climate change educational opportunities provided during their training by the respective veterinary programs, $86.7 \%$ (437/504) stated that no educational opportunities were available to them. Only $10.1 \%$ (51/504) of participants reported that educational opportunities did exist for them in the form of clubs (such as One Health, chapter of the Association for Veterinarians for the Environment, Public Health) or through core and elective courses [like Epidemiology, Parasitology, Public Health, Population Medicine, and One Health). Some participants (3.2\% (16/504)] were unaware of any education opportunities during their training. Of the available mechanisms through which climate change education could be provided to practicing veterinarians, continued education such as conferences and seminars was the most commonly selected option $(70.7 \%, 396 / 560)$, followed by core content in the veterinary medical curriculum $(42 \%, 235 / 560)$ and elective opportunities through veterinary societies $(40 \%$, 224/560). A small number of participants felt they did not know $(4 \%, 22 / 560)$. The most commonly shared write-in response was journal articles $(6.5 \%, 2 / 31)$.

Climate change topics that participants felt the veterinary community should be knowledgeable about can be found in Figure 5. The topics respondents chose as the highest priority for the veterinary community to be knowledgeable about were the economic impacts of climate change as related to animals (90.1\%, 446/495) and environmentally sustainable behaviors specific to veterinary medical practice $(89.9 \%, 445 / 495)$. Interest in a variety of climate and health resources is presented in Figure 6. Participants were most interested in receiving guidance on how to make their workplaces sustainable $(82.1 \%, 400 / 487)$ and having access to continuing education opportunities on climate change and health $(80.4 \%, 393 / 489)$. The most common open text resource suggestion was access to journal articles and current research on climate change. Other suggestions were continuing education and online resources, community outreach, policy and advocacy, methods to reduce biomedical waste, and access to environmentally friendly supplies.

In addition to the open text responses specific to questions described above, numerous respondents made comments pertaining to the impacts of climate change on veterinarian wellbeing. These included feeling blamed for animal contributions to climate change (ex. methane), exasperated financial stress secondary to economic ramifications, direct human health effects, and an inability to take action on climate change given the already overwhelming pressures of the profession. Respondents also reported the mental health impacts climate change imposes on veterinarians due to the concerns for animals and the environmental determinants of health upon which they are dependent.

\section{Non-U.S. Responses}

Although the survey targeted veterinarians from the U.S., 54 veterinarians from outside the U.S. also took the survey and responses were compared to those of the U.S. This group represented fifteen different countries of which Canada was most
TABLE 2 | Ways in which participants believe veterinary patients are currently being affected or will be affected in the next 10-20 years by climate change.

\begin{tabular}{|c|c|c|c|c|c|}
\hline Time period & Yes (\%) & No (\%) & Don't know (\%) & Rank & $N$ \\
\hline \multicolumn{6}{|c|}{ Increasing vector-borne diseases } \\
\hline Now & 83.2 & 6.6 & 10.2 & 1 & 519 \\
\hline Future (10-20y) & 86.4 & 4.2 & 9.4 & 1 & 403 \\
\hline \multicolumn{6}{|c|}{ Increasing extreme weather events } \\
\hline Now & 80.3 & 12.9 & 6.7 & 2 & 519 \\
\hline Future (10-20y) & 81.3 & 8.8 & 9.8 & 2 & 407 \\
\hline \multicolumn{6}{|c|}{ Increasing heat-associated illness/stress } \\
\hline Now & 66.2 & 19.3 & 14.5 & 3 & 517 \\
\hline Future (10-20y) & 73.0 & 11.5 & 15.5 & 5 & 407 \\
\hline \multicolumn{6}{|c|}{ Increasing water-associated illnesses/stress } \\
\hline Now & 61.9 & 17.8 & 20.3 & 4 & 517 \\
\hline Future (10-20y) & 75.1 & 9.9 & 15.1 & 4 & 405 \\
\hline \multicolumn{6}{|c|}{ Declining air quality } \\
\hline Now & 61.4 & 20.7 & 18.0 & 5 & 518 \\
\hline Future (10-20y) & 75.2 & 9.6 & 15.2 & 3 & 408 \\
\hline \multicolumn{6}{|c|}{ Reduced food safety, quality and security } \\
\hline Now & 47.4 & 32.4 & 20.2 & 6 & 515 \\
\hline Future (10-20y) & 60.9 & 16.4 & 22.7 & 6 & 409 \\
\hline
\end{tabular}

strongly represented $(n=18)$. The non-U.S. respondents did not differ from the U.S. respondents in gender or age $(p>0.05$ for both); however, they were generally more non-clinical (academic, industry or government) than clinical (all practice types, $p=$ $0.02)$ and more liberal $(p=0.01)$. All non-U.S. participants felt that climate change is happening at this time and more of them believe it is caused by humans $(p=0.02)$. Their level of knowledge regarding the human or animal health impacts of climate change does not differ from U.S. veterinarians $(p>$ 0.05 ) however they more strongly believe that climate change is directly relevant to patient care $(p=0.02)$. In general, non-U.S. participants agreed with U.S. veterinarians with respect to how ( $p>0.05$ for all), and which, animals are impacted by climate change except that statistically more non-U.S. veterinarians were concerned about extreme weather and heat $(p<0.05)$.

When asked about potential barriers that would prevent talking about climate change with clients, non-U.S. respondents were significantly less concerned about different political views of their clients $(p=0.02)$ and had a significantly stronger belief that they could make a difference in animal health $(p<0.01)$. They did share the concerns of U.S. veterinarians regarding time in appointments, client interest and lack of knowledge on the topic ( $p>0.5$ for all). Significantly more non-U.S. respondents felt that teaching about the environment and its association with health impacts should be incorporated into veterinary medical education, that veterinarians and veterinary medical societies should have a significant advocacy role in relation to climate change and health, and that veterinarians have a responsibility to bring the health effects of climate change to the attention of the public and their clients $(p<0.05$ for all). Non-U.S. veterinarians were similar to U.S. veterinarians in their belief 


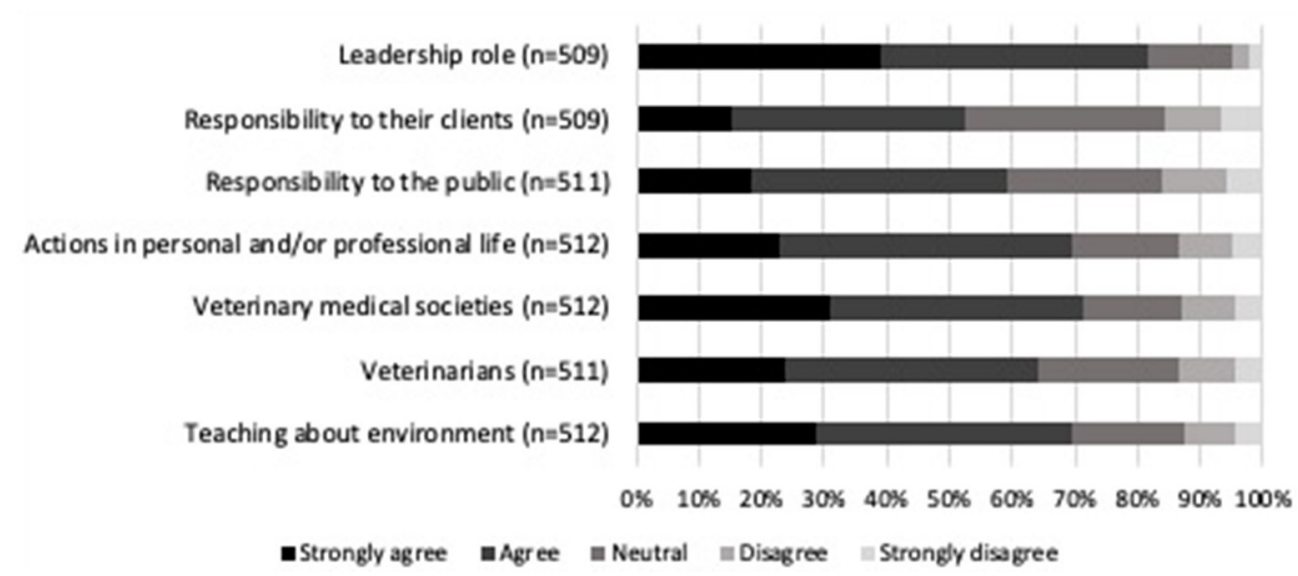

FIGURE 3 | Percentage of level of agreement or disagreement from veterinarians on the potential involvement of the veterinary profession on climate change and health. Complete statements can be found in Appendix 1.

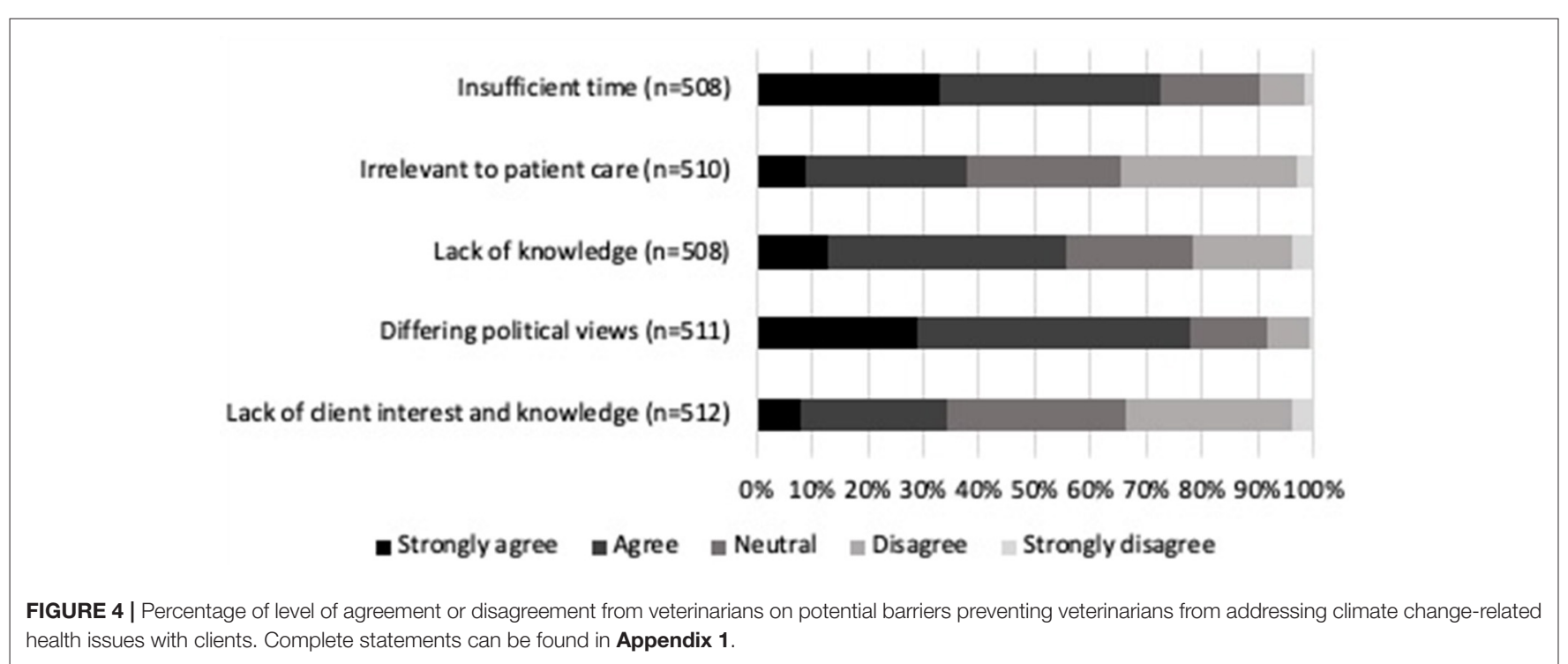

that veterinarians should have a leadership role in encouraging offices, clinics, and hospitals to be as environmentally sustainable as possible and that actions they take in their personal and professional lives contribute to effective action on climate change. As with U.S. respondents, the overwhelming majority of nonU.S. veterinarians $(89.5 \%, 43 / 48, p>0.05)$ did not learn, or do not remember learning, about climate change as part of their education. There was no statistically significant difference $(p>$ 0.05 for all) between U.S. and non-U.S. veterinarians regarding the topics that veterinarians should be knowledgeable about and the mechanisms in which it could be delivered.

\section{DISCUSSION}

Veterinary respondents overwhelmingly agree that climate change is occurring and that it is associated with a variety of human and animal health impacts. Overall, these results are similar to those of veterinary students (7) and human physicians (9-11). The majority of the respondents, and the target population, were U.S. veterinarians with a gender and employment distribution similar to the national average (12). Participants reported working in all types of communities (urban, suburban, rural) and shared diverse political beliefs spanning the political range.

Collectively, results of this study strongly support the need for veterinary education on the health impacts of climate change. Ninety percent of respondents had no, or were not aware of, exposure to this topic during their veterinary school education. This is in contrast to current veterinary students where $76 \%$ of respondents had no, or were not aware of, educational opportunities within their curriculum (7), indicating only a modest shift in veterinary training over time despite increased demand. Consistent with students, veterinary respondents reported being equally knowledgeable about the health impacts 


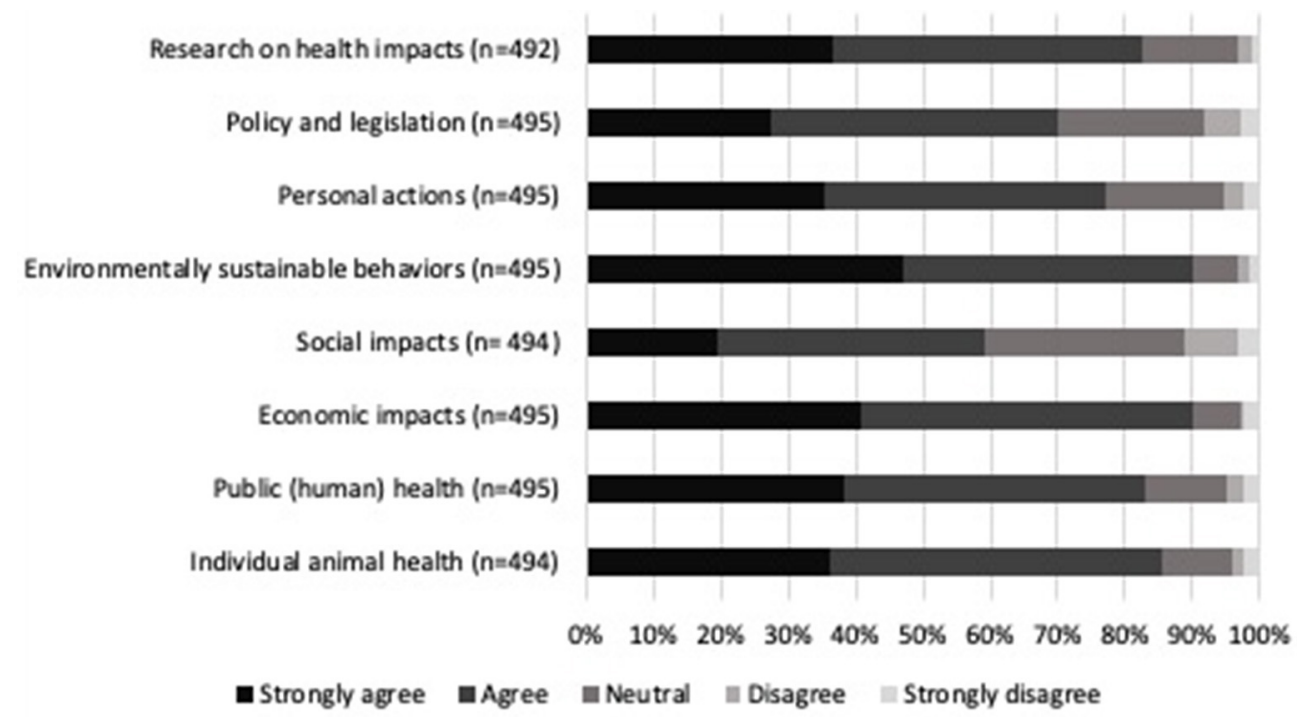

FIGURE 5 | Percentage of level of agreement or disagreement from veterinarians on climate change and health topics that the veterinary community should be knowledgeable about. Complete statements can be found in Appendix 1.

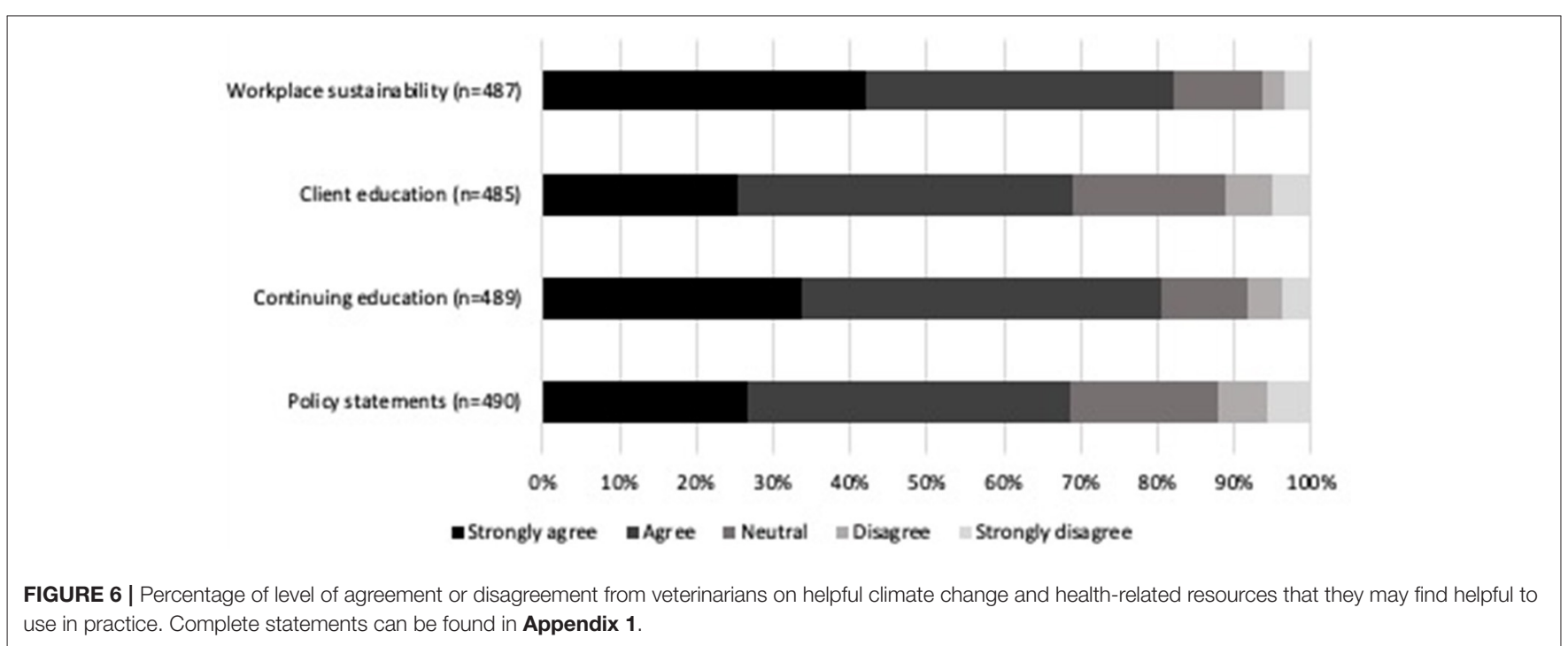

of climate change in humans as in animals, which is surprising given the focus of veterinary education is on animals. This result suggests that some of respondents' learning about climate change has been obtained from sources of information unrelated to or separate from their work with animals.

Most veterinarians recorded that they believe education on climate change should be provided through continuing education (CE) opportunities while others felt that incorporating educational opportunities into the core content of veterinary curricula would be the best option. Some veterinary schools have already integrated climate change into their curricula through classes such as preventative medicine, epidemiology, population medicine, and parasitology, indicating that it may not be as difficult as predicted to incorporate the topic of climate change into the core content. Another potential avenue for incorporating climate change education into the core curricula emphasizes building on existing models (i.e., One Health, epidemiology or preventative medicine classes, etc.) to reinforce intersecting health concepts (13). However, some respondents noted that veterinary curricula are already saturated with content and adding more coursework could be overwhelming.

A focus on CE may be a more feasible solution; creating such opportunities at conferences or through professional associations such as the AVMA, could be well-received. Such efforts could focus on priorities indicated by this, and previous (7), studies' respondents, including "encouraging offices, clinics, and hospitals to be as environmentally sustainable as possible." Veterinarians also prioritized knowledge about the economic 
impacts of climate change as related to animals. As every veterinary school in the United States has a Veterinary Business Management Association (VBMA) chapter with a business certificate program (14), the economic impacts of climate change on animal health could be integrated as a critical part of a CE program.

CE that addresses other challenges, such as difficult conversations with clients or colleagues around climate change, may appeal to others. Respondents felt that differences in political views damaging the veterinarian-client-patient relationship coupled with the lack of time during appointments are the largest potential barriers to addressing climate changerelated health impacts with clients. Although the concern that political opinions and differences of beliefs on climate change would inhibit progressive conversation, studies have shown that people, regardless of political party affiliation, are positively responsive to discussing climate change when taken from an approach based on health impacts (15-18). Development of CE programs that consider varying political orientations will require collaboration between health professionals and environmental education researchers (17). CE oriented on communications and difficult conversations for veterinarians to instruct them on the proper and least confrontational verbiage to use with clients could also be a path forward.

The veterinary profession, like other disciplines, could start providing continuing education opportunities on climate change through conventions and webinar series (19). Online learning has the potential to reach a broad audience, is accessible to many who do not have the time or resources to travel to in-person trainings and may exist in convenient online venues that people already visit (e.g., Facebook and LinkedIn). Certificate programs or other micro-credentials may provide useful motivation for individuals or practices to complete a training. In a recent survey of pet owners, most respondents valued knowing that their veterinary clinic had obtained a certification for their sustainability practices (20) suggesting that such educational programs may have economic cobenefits.

Despite the excellent learning opportunities that exist in many spheres, individual-level learning about conservation and sustainability does not typically translate to behavior change without clear motivational and social supports (21). Theories of social practice suggest collective behavior change is constrained by culture and context (22). Learning and subsequent action needs to be clearly connected to issues of local relevance (23), and supported by behavioral norms (24). In other words, it is easier to change people's behaviors when they are working to address a concrete, local issue rather than an abstract or distant one, and if the desired behaviors are socially acceptable.

With the social and contextual constraints in mind, approaches to behavior change need to provide more support for veterinarians who wish to learn more about climate change, build the sustainability efforts of their practices, and influence those around them, including clients, colleagues, and loved ones. Approaches such as Communities of Practice (25) are intended to provide support for participants' shared learning and may help mitigate negative messages learners receive elsewhere. Voluntary education grounded in social interaction has the downside that, at first, such efforts are likely to attract only like-minded individuals, meaning that skeptics are unlikely to participate. Yet as a community grows, it may start to shift the larger professional culture and, in this case, put useful social pressure on skeptics.

Building community around a shared area of interest may have additional co-benefits to veterinarians. Despite not being a topic on the survey, numerous write-in responses highlighted the impact of climate change on veterinarians' mental health and well-being. The direct and indirect mental health impacts associated with climate change are vast and increasing (26, 27). Veterinarians already struggle with significant mental health issues $(28,29)$; however, finding meaningful purpose, relationships, and personal growth can promote professional well-being (30). By supporting concerned veterinarians to engage in collective action on climate change, we may save more than just our environment.

Veterinary respondents agreed that their professional organizations could contribute through the development of policy statements on the topic and these are a logical place to begin building community. While this type of leadership has been seen in human medicine (5), it appears inconsistent in the animal health sector. As an example, when entering the profession, veterinarians around the world take a public oath of professionalism and standards. This declaration has evolved to reflect societal concerns such as animal welfare and environmental stewardship, however there are notable differences between countries (31). While the World Veterinary Association includes "to advocate for the sustainable use of terrestrial, aerial, and aquatic animals in their diverse ecosystems through stewardship to reduce environmental impacts," (32) and an interprofessional planetary health pledge has been proposed (33), there is no reference to the environment in the Veterinarians Oath from the AVMA (34). Although this omission has been postulated to reflect a national sentiment (31), it does not appear to reflect the perceptions of veterinarians responding to this survey as more than $90 \%$ believe that climate change is occurring, a number significantly higher than the $73 \%$ of the American general public (35). It may be appropriate for veterinary medical associations to assess their policies to ensure they best support their constituents and the public.

While the survey was designed for U.S. veterinarians, responses from non-U.S. veterinarians provided an interesting comparison group. Veterinarians outside of the U.S. were generally less concerned about politics, more strongly believed that climate change is directly relevant to patient care and feel more empowered to act beyond their personal and professional behaviors. While this small number of non-U.S. responses is grossly insufficient to make strong conclusions, it highlights areas for additional research. Similarly, given the convenience sampling of U.S. veterinarians, further work is needed to determine if the results of the present study are generalizable beyond the response group.

Climate change is the biggest global health threat of the Twenty-first century (1) and therefore of direct relevance to 
health professionals. Veterinarians, current and future (7), are similarly concerned about this growing health threat, but have received minimal to no formal education on the topic. However, taking action on climate change is within the scope of veterinary practice (8). Through the development of climate change educational opportunities and fostering a sense of community around these ideals, we can support veterinarians to be influential stewards of human, animal and environmental health.

\section{DATA AVAILABILITY STATEMENT}

The original contributions presented in the study are included in the article/Supplementary Material, further inquiries can be directed to the corresponding author.

\section{ETHICS STATEMENT}

The survey was reviewed and approved by the Colorado State University Institutional Review Board prior to distribution. Participants provided their informed consent to participate in this study.

\section{REFERENCES}

1. Costello A, AM, Allen A, Ball S, Bell S, Bellamy R, et al. Managing the health effects of climate change: Lancet and University College London Institute for Global Health Commission. Lancet. (2009) 373:1693-733. doi: 10.1016/S0140-6736(09)60935-1

2. Watts N, Amann M, Arnell N, Ayeb-Karlsson S, Belesova K, Berry H, et al. The 2018 report of the Lancet Countdown on health and climate change: shaping the health of nations for centuries to come. Lancet. (2018) 392:2479-514. doi: 10.1016/S0140-6736(18)32594-7

3. Maxwell J, Blashki G. Teaching about climate change in medical education: an opportunity. J Public health Res. (2016) 5:673-673. doi: 10.4081/jphr. 2016.673

4. Wellbery C, Sheffield P, Timmireddy K, Sarfaty M, Teherani A, Fallar R. It's time for medical schools to introduce climate change into their curricula. Acad Med. (2018) 93:1774-7. doi: 10.1097/ACM.0000000000002368

5. Association AM. AMA Adopts New Policies to Improve Health of Nation. (2016). Available online at: https://www.ama-assn.org/press-center/ press-releases/ama-adopts-new-policies-improve-health-nation (accessed November 6, 2020)

6. McGain F, Naylor C. Environmental sustainability in hospitals - a systematic review and research agenda. J Health Serv Res Policy. (2014) 19:245-52. doi: 10.1177/1355819614534836

7. Pollard A, Rowlison D, Kohnen A, McGuffin K, Geldert C, Kramer C, et al. Preparing veterinarians to address the health impacts of climate change: student perceptions, knowledge gaps and opportunities. J Vet Med Educ. (2020) 6:e20190080. doi: 10.3138/jvme-2019-0080

8. Stephen C, Carron M, Stemshorn B. Climate change and veterinary medicine: action is needed to retain social relevance. Can Vet J. (2019) 60:1356-8.

9. Sarfaty M, Bloodhart B, Ewart G, Thurston GD, Balmes JR, Guidotti TL, et al. American Thoracic Society Member Survey on climate change and health. Ann Am Thorac Soc. (2014) 12:274-8. doi: 10.1513/AnnalsATS.201410-460BC

10. Sarfaty M, Mitchell M, Bloodhart B, Maibach EW. A survey of African American physicians on the health effects of climate change. Int J Environ Res Public Health. (2014) 11:12473-85. doi: 10.3390/ijerph111212473

11. Sarfaty M, Kreslake JM, Casale TB, Maibach EW. Views of AAAAI members on climate change and health. J Allergy Clin Immunol. (2016) 4:333-5.e326. doi: 10.1016/j.jaip.2015.09.018

\section{AUTHOR CONTRIBUTIONS}

All authors were part of the design, execution and analysis of the project and were involved in drafting and approving the final manuscript.

\section{FUNDING}

Funding was provided by donation to Colorado State University.

\section{ACKNOWLEDGMENTS}

The authors would like to thank all the veterinarians who took the time to participate in this survey and share it with their colleagues.

\section{SUPPLEMENTARY MATERIAL}

The Supplementary Material for this article can be found online at: https://www.frontiersin.org/articles/10.3389/fvets. 2020.613620/full\#supplementary-material

12. AVMA. U.S. Veterinarians 2019. (2019). Available online at: https://www avma.org/resources-tools/reports-statistics/market-research-statistics-usveterinarians-2019 (accessed November 6, 2020).

13. Bell EJ. Climate change: what competencies and which medical education and training approaches? BMC Med Educ. (2010) 10:31. doi: 10.1186/1472-6920-10-31

14. VBMA. VBMA Our Mission. Available Online at: https://vbma.biz/ (accessed November 6, 2020).

15. Maibach EW, Nisbet M, Baldwin P, Akerlof K, Diao G. Reframing climate change as a public health issue: an exploratory study of public reactions. BMC Public Health. (2010) 10:299. doi: 10.1186/1471-2458-10-299

16. Wei JHA, Zhang Y, Li H, Liu Q, Sun Y, et al. Perception, attitude and behavior in relation to climate change: a survey among CDC health professionals in Shanxi province, China. Environ Res. (2014) 134:301-8. doi: 10.1016/j.envres.2014.08.006

17. Adlong W, Dietsch E. Environmental education and the health professions: framing climate change as a health issue. Environ Educ Res. (2015) 21:687-709. doi: 10.1080/13504622.2014.930727

18. Hathaway J, Maibach EW. Health implications of climate change: a review of the literature about the perception of the public and health professionals. Current Environ Health Reports. (2018) 5:197-204. doi: 10.1007/s40572-018-0190-3

19. Robelia BA, Greenhow C, Burton L. Environmental learning in online social networks: adopting environmentally responsible behaviors. Environ Educ Res. (2011) 17:553-75. doi: 10.1080/13504622.2011.565118

20. Scott D, Deluty S, Martin V, McCaw K, Rupert J, Waugh S, et al. The Value of Sustainability in Veterinary Practice: A Client Perspective. In: $20^{\text {th }}$ Annual CSU CBMBS Research Day. Fort Collins, CO (2019).

21. McKenzie-Mohr D, Schultz PW, Lee N, Kotler P. Social Marketing to Protect the Environment: What Works. Thousand Oaks, CA: SAGE Publications, Inc. (2012). doi: 10.4135/9781483349466

22. Hargreaves T. Practice-ing behaviour change: applying social practice theory to pro-environmental behaviour change. J Consumer Culture. (2011) 11:7999. doi: 10.1177/1469540510390500

23. Uzzell DL. The psycho-spatial dimension of global environmental problems. J Environ Psychol. (2000) 20:307-18. doi: 10.1006/jevp.2000.0175

24. Clayton SD, Schultz PW, Kaiser FG. Promoting Pro-Environmental Behavior. New York, NY: Oxford University Press. (2012). 
25. Wenger E. Communities of Practice and Social Learning Systems: the Career of a Concept. In: Social Learning Systems and Communities of Practice, C Blackmore, ed. London: Springer London (2010) 179-98. doi: 10.1007/978-1-84996-133-2_11

26. Bourque F, Cunsolo Willox A. Climate change: the next challenge for public mental health? Int Rev Psychiatry. (2014) 26:415-22. doi: 10.3109/09540261.2014.925851

27. Hayes K, Blashki G, Wiseman J, Burke S, Reifels L. Climate change and mental health: risks, impacts and priority actions. Int J Ment Health Syst. (2018) 12:28. doi: 10.1186/s13033-0180210-6

28. Nett RJ, Witte TK, Holzbauer SM, Elchos BL, Campagnolo ER, Musgrave KJ, et al. Risk factors for suicide, attitudes toward mental illness, and practice-related stressors among US veterinarians. J Am Vet Med Assoc. (2015) 247:945-55. doi: 10.2460/javma.247. 8.945

29. Best CO, Perret JL, Hewson J, Khosa DK, Conlon PD, Jones-Bitton A. A survey of veterinarian mental health and resilience in Ontario, Canada. Can Vet J. (2020) 61:166-72.

30. Cake MA, Bell MA, Bickley N, Bartram DJ. The life of meaning: a model of the positive contributions to well-being from veterinary work. J Vet Med Educ. (2015) 42:184-93. doi: 10.3138/jvme.1014097R1

31. Bones VC, Yeates JW. The emergence of veterinary oaths: social, historical, and ethical considerations. J Animal Ethics. (2012) 2:20-42. doi: 10.5406/janimalethics.2.1.0020
32. World Veterinary Association (WVA). World Veterinary Association Model Veterinarians' Oath. Available Online at: http://www.worldvet.org/uploads/ news/docs/wva_model_veterinarians_oath.pdf (accessed November 6, 2020).

33. Wabnitz K-J, Gabrysch S, Guinto R, Haines A, Herrmann M, Howard C, et al. A pledge for planetary health to unite health professionals in the Anthropocene. Lancet. (2020) 396:1471-3. doi: 10.1016/S0140-6736(20)32039-0

34. AVMA Veterinarian's Oath. Available online at: https://www.avma.org/ resources-tools/avma-policies/veterinarians-oath (accessed November 6, 2020).

35. Gustafson A, Bergquist P, Leiserowitz A, Maibach EW. A Growing Majority of Americans Think Global Warming is Happening and are Worried. In: Yale Program on Climate Change Communication. New Haven, CT: Yale University and George Mason University. (2019).

Conflict of Interest: The authors declare that the research was conducted in the absence of any commercial or financial relationships that could be construed as a potential conflict of interest.

Copyright (c) 2020 Kramer, McCaw, Zarestky and Duncan. This is an open-access article distributed under the terms of the Creative Commons Attribution License (CC $B Y)$. The use, distribution or reproduction in other forums is permitted, provided the original author(s) and the copyright owner(s) are credited and that the original publication in this journal is cited, in accordance with accepted academic practice. No use, distribution or reproduction is permitted which does not comply with these terms. 